\title{
Determining a BMDL of Blood Lead Based on ADHD Scores Using a Semi-Parametric Regression
}

\author{
Ah Hyoun Kim ${ }^{1} \cdot$ Mina $\mathrm{Ha}^{2} \cdot$ Byung Soo Kim ${ }^{3}$ \\ ${ }^{1}$ Department of Applied Statistics, Yonsei University; ${ }^{2}$ College of Medicine, Dankook University \\ ${ }^{3}$ Department of Applied Statistics, Yonsei University
}

(Received April 10, 2012; Revised April 26, 2012; Accepted May 25, 2012)

\begin{abstract}
This paper derives a benchmark dose(BMD) and its 95\% lower confidence limit(BMDL) using a semiparametric regression model for small lead based changes in attention-deficit hyperactivity disorder(ADHD) scores in the first wave of the Children's Health and Environment Research(CHEER) survey data, which have been regularly collected in South Korea since 2005. Ha et al. (2009) showed that the appearance of ADHD symptoms had a borderline trend of increasing with the blood lead concentration. Butdz-Jørgensen (EFSA, 2010a) derived the BMDL of lead corresponding to a benchmark region of 1 full intelligent quotient (IQ) score using the raw data in Lanphear et al. (2005, EHP). European Food Safety Authority (EFSA, $2010 \mathrm{~b}$ ) determined the BMDL of $1.2 \mathrm{\mu g} / \mathrm{dl}$ as a reference point for the characterization of lead when assessing the risk of the intellectual deficit measured by IQ scores. Kim et al. (2011) indicated that an even lower BMDL could be obtained based on the ADHD score; however, the BMDLs depended heavily upon the model assumptions. We show in this paper that a semi-parametric approach resolves the model dependence of BMDLs.
\end{abstract}

Keywords: Attention deficit hyperactivity disorder, benchmark dose lower limit, reference point, semiparametric regression.

\section{1. 서론}

납은 자연 상태에서 나타나는 독성 물질로 주로 식품이나 음용수, 공기, 토양 등을 통해 인체에 노출된 다. 그 중 식품이 가장 주요한 납의 노출원인데, 노출된 납은 인체에 오랜 시간 머물러 높은 축적성을 보이는 것으로 알려져 있다. 납이 인체에 흡수되는 경로는 먼저 위장관, 호흡기, 식도 등을 통해 흡수된 후, 혈액 중 적혈구와 결합되어 간이나 신장 등 신체의 여러 곳을 통해 최종적으로는 뼈에 축적된다. 따 라서 납이 인체에 미치는 효과는 주로 혈중 납 농도를 기초로 파악되며, 뼈나 치아의 납 농도는 과거 납 의 폭로 정보를 나타낸다 (EFSA, 2010b).

납이 인체에 미치는 여러 해효과에 대해서는 다양한 연구가 이루어져 왔으며, 특히 아동을 대상으로 한 연구에서는 납이 아동의 지적 능력 저하, 인지기능 저하, 행동장애, 학교성적저하 등을 야기하는 것으 로 보고된 바 있다 (Lanphear 등, 2005). 아동에 대해 주의를 요하는 혈중 납 농도 수준은 2005년 이

\footnotetext{
${ }^{3}$ Corresponding author: Department of Applied Statistics, Yonsei University, 50 Yonsei-ro, Seodaemun-gu,
} Seoul 120-749, Korea. E-mail: bskim@yonsei.ac.kr 
전의 연구에서는 $10 \mu \mathrm{g} / \mathrm{dl}$ 로 제시하였으며 (US CDC, 2005), 이를 1 주일 간 섭취 가능량(Provisional Tolerable Weekly Intake; PTWI)으로 환산하면 $25 \mu \mathrm{g} / \mathrm{kg}$ b.w/day에 해당한다 (JFCFA, 2000). 그런 데 이에 앞서 국제보건기구 (WHO, 1995)와 미국 질병통제센터 (US CDC, 1991)의 보고에 따르면, 납 노출에 대한 해효과는 역치가 없을 것이며 $10 \mu \mathrm{g} / \mathrm{dl}$ 보다 적은 혈중 납 농도도 인체에 해효과를 미칠 만 큼의 독성을 가질 것이라고 추측하였으나, 이를 지지하는 구체적인 자료는 Canfield 등 (2003)에서 처음 보고되었다.

이어서 과거 기준치였던 $10 \mu \mathrm{g} / \mathrm{dl}$ 가 적절한 수준이 아니며, 납이 인체에 미치는 해효과에는 역치가 존 재한다는 증거가 없다는 것이 여러 연구를 통해서 밝혀졌다. 특히 아동의 지적 능력을 저하시키는 것 에 관한 것으로 Lanphear 등 (2005)은 혈중 납 농도가 $10 \mu \mathrm{g} / \mathrm{dl}$ 보다 적은 경우에도 아동의 지적 결 핍을 야기할 수 있음을 밝혔다. 이들은 전 세계 7 개 지역에서 아동을 대상으로 수년에 걸쳐 수집된 코 호트(cohort) 자료를 통합하여 메타분석을 수행하였으며, 그 결과 $7.5 \mu \mathrm{g} / \mathrm{dl}$ 이하의 혈중 납 농도도 아 동의 지적 수준을 저해할 수 있음을 보였다. 한편 Butdz-Jørgensen (EFSA, 2010a)은 Lanphear 등 (2005)의 연구에서 사용한 7 개 경시적 자료에 기초하여 아동의 $\mathrm{IQ}$ 점수를 1점 저하시키는 혈중 납 농도 의 $95 \%$ 신뢰하계를 $1.2 \mu \mathrm{g} / \mathrm{dl}$ 로 도출하였다.

한국의 경우 지난 40 년간 빠르게 진행된 산업화 과정에서 다양한 유해 물질이 배출되어 환경을 오염시 켰으며, 이로 인해 아동이 신경발달장애를 겪을 수 있다는 가설이 주목을 받고 있다 (Ha 등, 2009). 실 제로 주의력결핍 과잉행동장애(attention deficit hyperactivity disorder; ADHD)로 치료를 받은 5 세부 터 14 세 사이의 아동의 수는 2003 년 16,607 명에서 2011 년 51,657 명으로 증가하였으며, 질환 아동의 수 가 가장 많은 나이 그룹이 5-9세에서 10-14세로 바뀌었다고 보고되고 있다 (국민건강보험정책연구원, 2011). 환경부에서는 2005 년부터 한국 아동의 건강에 환경이 어떠한 영향을 미치는가를 파악하기 위한 장기간의 코호트 조사로 CHEER(Children's Health and Environment Research) 연구를 시작하였다.

본 연구에서는 납과 아동의 주의력 결핍 과잉행동장애 $(\mathrm{ADHD})$ 와의 상관성을 파악하고자 한다. 이와 관 련된 선행 연구로 $\mathrm{Ha}$ 등 (2009)은 CHEER 자료를 이용하여 아동의 혈중 납 농도가 ADHD 증상을 유 의적으로 심화시킬 수 있음을 보였다. 또한 Kim 등 (2011)는 Butdz-Jørgensen (EFSA, 2010a)과 유 사한 방법을 이용하여 CHEER 자료를 분석한 결과, 아동의 $\mathrm{ADHD}$ 지표를 약간 상승하게 만드는 혈 중 납 농도의 $95 \%$ 신뢰하계가 $1.2 \mu \mathrm{g} / \mathrm{dl}$ 보다 적어짐을 보였다. 본 연구에서도 동일한 CHEER 자료 를 이용하여 아동의 $\mathrm{ADHD}$ 지표를 약간 상승하게 만드는 혈중 납 농도의 $95 \%$ 신뢰하계을 산출하였는 데, Kim 등 (2011)의 연구와 주요한 차이점은 선형 회귀모형이 아닌 준모수 회귀모형(semi parametric regression model)을 적용하였다는 점이다. Kim 등 (2011)의 연구에서는 자료에 변수변환을 취하거나 모형을 확장 또는 축소하였을 때 추정치가 불안정하다는 점이 한계였으나, 본 연구에서는 준모수 회귀모 형을 이용함으로써 추정치가 모형에 의존적이었던 문제를 해결해 보고자 한 것이다.

본 연구의 구성은 다음과 같다. 2장에서는 본 연구에 활용한 CHEER 자료 및 변수를 정의하고 벤치마 크 용량에 관한 선행연구에 대해 살펴보며, 3 장에서는 준모수적 모형을 구성하였다. 4 장에서 모형의 적 합 결과와 해석을 제시하고, 5 장에서는 벤치마크 용량을 도출하기 위한 방법을 밝힌 뒤, 4 장에서의 모형 적합 결과를 이용하여 산출된 벤치마크 용량의 값을 제시하고, 6 장에서는 내용을 종합해 결론을 맺는다.

\section{2. 자료 및 벤치마크 용량}

\subsection{CHEER 자료}

CHEER 자료는 환경부에서 2005년부터 한국 아동의 건강과 환경에 관한 연구를 위해 수집한 자료 로, 아동의 $\mathrm{ADHD}$ 에 대한 심각성을 30 점 척도로 지표화한 점수와 혈중 납 농도, 부모의 소득 및 교 
Table 2.1. Variables in CHEER data set

\begin{tabular}{|c|c|c|c|}
\hline 변수 & 변수명 & 타입 & 단위 \\
\hline 혈중 납 농도 & Pb_W_B & 연속형 & $\mu \mathrm{g} / \mathrm{dl}$ \\
\hline $\mathrm{ADHD}$ 지표 & ADHD & 연속형 & $0 \sim 30$ \\
\hline 성별 & $\operatorname{sex}$ & 범주형 & $0=$ 남자, $1=$ 여자 \\
\hline 아버지의 교육수준 & dad_edu_yr & 연속형 & 년 \\
\hline 임신 중 흡연여부 & smk_dur_preg & 범주형 & $\begin{array}{l}0=\text { 없음 }, 1=\text { 있음 } \\
\text { 각 계급 별 중앙값 사용 } \\
\left(\begin{array}{ll}250 & \text { (500미만), } \\
750 & \text { (500이상 } 1000 \text { 미만 }),\end{array}\right.\end{array}$ \\
\hline 부모의 소득 & income & 연속형 & $\left(\begin{array}{ll}1500 & \text { (1000이상 } 2000 \text { 미만), } \\
2500 & \text { (2000이상 } 3000 \text { 미만), } \\
4000 & \text { (3000이상 } 5000 \text { 미만), } \\
7000 & \text { (5000이상 })\end{array}\right.$ \\
\hline 임신 중 음주여부 & alc_dur_preg & 범주형 & $0=$ 없음, $1=$ 있음 \\
\hline 부모의 신경정신질환여부 & fdr_neurop & 범주형 & $0=$ 없음, $1=$ 있음 \\
\hline
\end{tabular}

육수준 등 유용한 공변수를 포함하고 있다. 이는 한국 6 개의 도시에서 1,873 명의 아동의 보호자를 대상으로 조사되었으며, 아동의 나이, 키, 몸무게의 평균(표준편차)는 각각 $7(0.8)$ 세, $121.2(9.9) \mathrm{cm}$, $27.5(6.4) \mathrm{kg}$ 이며, 아동의 혈중 납 농도의 중앙값(5 95 백분위수)은 $1.93(0.660 \sim 3.590) \mu \mathrm{g} / \mathrm{dl}$ 이다. 보 호자는 아동의 $\mathrm{ADHD}$ 증상을 한국 아동에 맞게 수정된 Conner 척도 (So 등, 2003)을 이용하여 검사하 였는데, 이는 10 개의 문항으로 구성되어 있으며 각 문항별로 $0,1,2,3$ 의 점수를 부여하는 검사이다. 최 종 $\mathrm{ADHD}$ 지표는 모든 점수를 합산하여 도출되며 점수가 높을수록 $\mathrm{ADHD}$ 증상이 심각한 것으로 볼 수 있다. 본 연구에서 $\mathrm{ADHD}$ 지표를 설명하기 위한 모형에 활용된 변수에 관한 구체적인 내용은 Table 2.1 에 정리되어 있다.

\section{2. 벤치마크 용량}

$\mathrm{BMD}$ (benchmark dose)란 독성 물질에 노출되지 않은 관찰치에 비해 사전에 정해진 만큼의 반응값의 증감을 야기하는 독성 물질의 양으로 정의되며, 여기서 반응값의 증가분은 BMR(benchmark region), $\mathrm{BMD}$ 의 $95 \%$ 신뢰하계를 BMDL(benchmark dose limit)이라 부른다. 앞서 소개한 Butdz-Jørgensen (EFSA, 2010a)의 연구를 예로 들어보면, 아동의 IQ 점수 1점에 대응되는 것이 $\mathrm{BMR}$ 이고, IQ 점수 1 점 하락을 야기하는 혈중 납 농도인 $\mathrm{BMD}$ 가 $1.8 \mu \mathrm{g} / \mathrm{dl}$ 로 도출되었다. 또, 이에 대한 $95 \%$ 신뢰하계 인 $\mathrm{BMDL}$ 이 $1.2 \mu \mathrm{g} / \mathrm{dl}$ 로 보고되었다. 즉, $\mathrm{BMDL}$ 은 인체 안전 기준을 산정하는 독성 물질의 기준값 이라 볼 수 있는데, BMDL 이전에 활용되었던 독성 기준값인 NOAEL(No Observed Adverse Effect Level)을 대체하기 위하여 만들어진 개념이다.

NOAEL은 대조군과 유의한 차이를 나타내지 않는 최대 실험 용량을 의미하며, 기본적으로 노출과 반 응의 관계에 역치가 존재할 것으로 보고 만들어진 개념이므로 혈중 납 농도와 같이 역치 존재를 입증 하기 힘든 독성 물질의 영향을 파악하기에 적합하지 않다. 뿐만 아니라 NOAEL 추정치는 실험설계에 의존적이며, 가설검정의 맥락에서 정의되었기 때문에 표본이 적어질수록 잠재적 독성 물질을 시장에 출 하하려는 제조업자에게 득이 된다는 모순을 안고 있다. 이에 대한 대안으로, Crump (1984)는 이진형 자료의 BMD 산출 방법론을 제안하였으며, 연속형 자료에 대해서는 Gaylor와 Slikker (1990), Crump (1995)에 의해 고안되었는데, 이상의 방법론은 모두 동물 실험 자료를 대상으로 한 것이었다. 
한편, 사람을 대상으로 하는 관찰 연구의 경우 해당 물질에 전혀 노출되지 않은 대조군을 찾기 힘들며, 반응 변수가 노출 변수 이외의 여타 중첩 변수에 의하여 영향을 받기 마련이다. Butdz-Jørgensen 등 (2001)은 기존의 실험 자료에 대한 $\mathrm{BMD}$ 접근법을 확장하여 관찰 연구에서 $\mathrm{BMD}$ 및 $\mathrm{BMDL}$ 을 산출 하는 방법을 제안하였으며, 페로 제도(Faroe Islands)의 아동에 대한 관찰 자료를 이용하여 신경심리적 장애의 척도인 $\mathrm{BNT}$ (Boston Naming Test) 점수에 대한 수은의 BMDL를 도출하였다. 이후에 ButdzJørgensen (EFSA, 2010a)은 Butdz-Jørgensen 등 (2001)에서 고안한 방법을 활용하여 아동의 IQ 점수 를 1점 저하시키는 혈중 납 농도의 $\mathrm{BMDL}$ 을 도출하였으며, 본 연구에서도 $\mathrm{ADHD}$ 에 대한 혈중 납 농도 의 $\mathrm{BMD}$ 를 산출하는데 이와 유사한 방식으로 접근하였다.

Butdz-Jørgensen (EFSA, 2010a)의 연구에서 활용된 BMD와 BMDL의 산출 방법론은 다음과 같 다. 먼저 관찰 연구에서는 노출 변수 이외의 변수에 의해 반응 변수가 영향을 받게 되므로 아래 식 (2.1)과 같이 확장된 모형을 고려해야 한다. 아래 모형에서 $Y$ 는 반응 변수를 나타내며 $d$ 는 노출 변수, $c_{1}, \ldots, c_{k}$ 는 그 외의 변수를 각각 의미한다.

$$
Y\left(d, c_{1}, \ldots, c_{k}\right)=\beta f(d)+\beta_{0}+\beta_{1} c_{1}+\cdots+\beta_{k} c_{k}+\epsilon,
$$

단, $\epsilon \sim N\left(0, \sigma_{\epsilon}^{2}\right), f$ 는 단조함수이고 $f(0)=0$.

즉, 위 모형에서 $\beta$ 의 추정치를 도출하면, $\hat{\beta} f(d)$ 이 $\mathrm{BMR}$ 이 되며, 이러한 $\mathrm{BMR}$ 에 대응되는 $d$ 의 값이 $\mathrm{BMD}$ 가 된다. $\mathrm{BMD}$ 의 $95 \%$ 신뢰하계가 $\mathrm{BMDL}$ 이므로, 그 산출 식은 아래 식 $(2.2)$ 와 같다.

$$
\hat{\beta}_{u} f(d)=\mathrm{BMR}, \quad \text { 단, } \hat{\beta}_{u}=\hat{\beta}+1.645 \mathrm{se}(\hat{\beta}) .
$$

한편, BMDL을 산출하기 위하여 위 식 (2.2)를 이용하는 대신 모수적 붓스트랩(bootstrap) 방법을 이 용할 수도 있다. 기존 모형에서의 반응값 추정치에 랜덤하게 발생한 오차 등을 더하여 반응변수를 재생 성한 뒤, 그 반응변수를 이용해서 모형을 새로 적합하면 $\mathrm{BMD}$ 도 새로 산출할 수 있는데, 이 과정을 반 복하여 $\mathrm{BMD}$ 의 분포를 얻은 뒤 하위 $5 \%$ 에 해당하는 값으로 $\mathrm{BMDL}$ 을 구하는 방식이다. 본 연구에서 활용하는 준모수적 회귀모형에는 붓스트랩 방식을 이용하는 것이 더 적절하므로, 본 연구에서도 이상의 방식을 이용하여 BMDL을 도출하였다.

\section{3. 준모수적 모형}

본 연구는 기본적으로 앞서 정의한 설명변수 가운데 자료의 종류가 명목형의 경우는 모수적 인자로, 혈 중 납의 농도를 포함한 모든 연속형 설명변수는 비모수적 인자일 수도 있다는 가능성을 염두에 두고 모 형을 처음 설계한 뒤, 이들 변수를 비모수적 인자로 가정하는 것이 적절한가에 대한 검토 후 최종 모형 을 구성하였다. 앞서 밝힌 바와 같이 $\mathrm{ADHD}$ 지표를 설명하는데 의미있는 7 가지 설명변수는 Pb_W_B, sex, dad_edu_yr, smk_dur_preg, income, alc_dur_preg, fdr_neurop이며, 이들 변수로 ADHD를 설명하 기 위한 모형을 아래 모형 1 과 같이 구성하였다. 아래 모형에서 연속형 자료인 Pb_W_B, dad_edu_yr, income은 우선 비모수적 인자로 가정하며, 나머지는 가변수로 구성하였다. 또한 아래 식에서 두 번째 등호는 주어진 모형의 비모수적 인자를 벌점화 스플라인(penalized spline)으로 두고 정의된 식으로, 각 해당 비모수적 변수 별 계수인 $u_{k}^{p}, \ldots, u_{k}^{I}$ 의 값이 커지지 않도록 제약을 둔 상태로 각 계수의 최소제곱 추정량(least square estimators)을 도출해야 한다.

모형 1

$$
\mathrm{ADHD}=\beta_{0}+f\left(\mathrm{~Pb}_{-} \mathrm{W}_{-} \mathrm{B}\right)+\beta_{s} \cdot \mathrm{sex}+g(\text { dad_edu_yr })+\beta_{m} \cdot \text { smk_dur_preg }+h(\text { income })
$$


Table 3.1. Check of the nonlinear relationship of continuous explanatory variables against the response

\begin{tabular}{cccc}
\hline Pb_W_B & dad_edu_yr & income & AIC \\
\hline 비선형 & 선형 & 선형 & 9553.40 \\
선형 & 비선형 & 선형 & 9553.54 \\
선형 & 선형 & 비선형 & 9546.06 \\
비선형 & 선형 & 비선형 & 9545.89 \\
선형 & 비선형 & 비선형 & 9546.06 \\
비선형 & 비선형 & 비선형 & 9545.89 \\
\hline
\end{tabular}

$$
\begin{aligned}
& +\beta_{a} \cdot \text { alc_dur_preg }+\beta_{f} \cdot \mathrm{fdr} \_n e u r o p+\epsilon \\
= & \beta_{0}+\beta_{p} \cdot \mathrm{Pb} \_\mathrm{W} \_\mathrm{B}+\sum_{k=1}^{K_{p}} u_{k}^{p}\left(\mathrm{~Pb} \_\mathrm{W} \_\mathrm{B}-\kappa_{k}^{p}\right)_{+}+\beta_{s} \cdot \mathrm{sex}+\beta_{d} \cdot \text { dad_edu_yr } \\
& +\sum_{k=1}^{K_{d}} u_{k}^{d}\left(\text { dad_edu_yr }-\kappa_{k}^{d}\right)_{+}+\beta_{m} \cdot \text { smk_dur_preg }+\beta_{I} \cdot \text { income }+\sum_{k=1}^{K_{I}} u_{k}^{I}\left(\text { income }-\kappa_{k}^{I}\right)_{+} \\
& +\beta_{a} \cdot \text { alc_dur_preg }+\beta_{f} \cdot \mathrm{fdr} \_ \text {neurop }+\epsilon,
\end{aligned}
$$

단, $\epsilon \sim N\left(0, \sigma_{\epsilon}^{2}\right)$ 이고, 모형에서 모수적 변수의 계수는 각각 $\beta_{s}, \beta_{m}, \beta_{a}, \beta_{f}$, 비모수적 변수의 계수는 $u_{k}^{p}, \ldots, u_{k}^{I}$ 이고, $C_{p}, C_{d}, C_{I}$ 가 사전에 주어진 상수(평활 모수와 일대일 대응)라고 할 때 $\sum_{k=1}^{K_{p}}\left(u_{k}^{p}\right)^{2}<$ $C_{p}, \sum_{k=1}^{K_{d}}\left(u_{k}^{d}\right)^{2}<C_{d}, \sum_{k=1}^{K_{I}}\left(u_{k}^{I}\right)^{2}<C_{I}$ 를 만족한다. 그리고 $f, g, h$ 는 각 비모수적 변수 별 평활 함수 를 나타내며, $\kappa_{1}^{p}, \ldots, \kappa_{K_{p}}^{p}, \kappa_{1}^{d}, \ldots, \kappa_{K_{d}}^{d}, \kappa_{1}^{I}, \ldots, \kappa_{K_{I}}^{I}$ 는 각 해당 변수 별 매듭 $(\mathrm{knots})$ 을 의미하고, 절단 함수인 $u_{+}$는 $u>0$ 인 경우는 $u$, 그렇지 않은 경우 0 인 함수로 정의된다.

위 모형에서 비선형 함수인 $f, g, h$ 의 평활 정도를 결정해야 하는데, 이는 평활 모수(smoothing parameter)와 대응 관계에 있는 $f, g, h$ 각각의 자유도 $d f_{p}, d f_{d}, d f_{I}$ 에 반영되며 본 연구에서는 이를 REML 방 법을 이용하여 추정하였다 (Ruppert 등, 2003). $f, g, h$ 의 자유도 $d f_{p}, d f_{d}, d f_{I}$ 의 REML 추정치는 위 모 형 1 을 혼합효과모형(Mixed Effect Model)로 재구성한 뒤, 그 모형에서의 모수인 랜덤 효과와 오차항 의 분산에 대한 최선선형불편예측치(BLUP)를 이용하여 구할 수 있으며, 본 연구에서 이러한 BLUP의 추정은 $\mathrm{R}$ 의 $\mathrm{lme}$ 함수를 이용하였다. CHEER 자료에 대해 이상의 논의된 바에 따라 모형을 적용한 결 과, $\mathrm{Pb} \_\mathrm{W} \_\mathrm{B}$ 의 함수 $f$ 는 자유도를 $d f_{p}=1.473$, dad_edu_yr의 함수 $g$ 는 자유도를 $d f_{d}=1.000$, income의 함수 $h$ 는 자유도를 $d f_{I}=2.614$ 로 두는 것이 적절한 것으로 도출되었다.

한편, 모형 1 에서는 모든 연속형 변수를 비모수적 인자로 가정하였는데, 이러한 가정이 적절한가에 대한 검토가 필요하다. 즉 $\mathrm{Pb} \_\mathrm{W} \_\mathrm{B}$, dad_edu_yr, income가 반응 변수인 $\mathrm{Pb} \_\mathrm{W} \_\mathrm{B}$ 와 비선형의 관계 를 가지는가에 대한 것이다. 우선 탐색적 분석으로 아래 Figure 4.1의 산점도를 살펴보면 $\mathrm{ADHD}$ 를 dad_edu_yr에 대한 비선형함수로 보기 어렵다는 것을 알 수 있다. 또한 Table 3.1에서 확인되듯이 dad_edu_yr는 선형, $\mathrm{Pb} \_\mathrm{W} \_\mathrm{B}$, income는 비선형 관계로 가정하는 것이 $\mathrm{AIC}$ 기준에서 적합도가 가장 좋아 이를 최종 모형으로 채택하기로 하였다.

이상의 내용을 종합하면 반응 변수인 $\mathrm{ADHD}$ 를 7 개의 설명변수 $\left(\mathrm{Pb} \_\mathrm{W} \_\mathrm{B}\right.$, sex, dad_edu_yr, smk_durpreg, income, alc_dur_preg, fdr_neurop)로 설명하는 모형을 구성하되, $\mathrm{Pb} \_\mathrm{W} \_B$ 는 자유도가 1.473인 비모수적 인자로, income은 자유도가 2.614인 비모수적 인자로 두고 나머지 5 개의 변수인 sex, dadedu_yr, smk_dur_preg, alc_dur_preg, fdr_neurop는 모수적 인자로 두는 준모수 회귀모형이 적정한 것 으로 판단된다. 최종 모형인 모형 2 는 다음과 같이 구성된다. 
모형 2

$$
\begin{aligned}
\mathrm{ADHD}= & \beta_{0}+f\left(\mathrm{~Pb} \_\mathrm{W} \_\mathrm{B}\right)+\beta_{s} \cdot \mathrm{sex}+\beta_{d} \cdot \text { dad_edu_yr }+\beta_{m} \cdot \text { smk_dur_preg } \\
& +h(\text { income })+\beta_{a} \cdot \text { alc_dur_preg }+\beta_{f} \cdot \mathrm{fdr} \_n e u r o p+\epsilon \\
= & \beta_{0}+\beta_{p} \cdot \mathrm{Pb} \_\mathrm{W} \_\mathrm{B}+\sum_{k=1}^{K_{p}} u_{k}^{p}\left(\mathrm{~Pb} \_\mathrm{W} \_\mathrm{B}-\kappa_{k}^{p}\right)_{+}+\beta_{s} \cdot \mathrm{sex}+\beta_{d} \cdot \text { dad_edu_yr } \\
& +\beta_{m} \cdot \text { smk_dur_preg }+\beta_{I} \cdot \text { income }+\sum_{k=1}^{K_{I}} u_{k}^{I}\left(\text { income }-\kappa_{k}^{I}\right)_{+}+\beta_{a} \cdot \text { alc_dur_preg } \\
& +\beta_{f} \cdot \text { fdr_neurop }+\epsilon,
\end{aligned}
$$

단, $\epsilon \sim N\left(0, \sigma_{\epsilon}^{2}\right)$ 이고, 기타 표기에 대한 정의는 식 (3.1)과 유사하다.

\section{4. 모형 적합 결과}

$\mathrm{R}$ 의 gam 함수를 이용하여 CHEER 자료에 대하여 위 모형 2 을 적합하였다. 결과 중 일부를 살펴보기 위하여 아래 Figure 4.1에서 아동의 혈중 납 농도, 아버지의 교육수준, 소득 수준, 부모의 신경정신질환 여부와 반응변수인 $\mathrm{ADHD}$ 간의 산점도를 보여주고 있다. 산점도에서 추정된 $\mathrm{ADHD}$ 의 값을 선으로 표 현하여 적합의 정도를 비교할 수 있도록 하였는데, 추정치에 해당하는 값은 수평축의 기준변수를 제외 한 나머지 설명변수의 평균값을 추정된 회귀식에 대입하여 계산된 것이다. 추정된 결과를 살펴보면 우 선 $\mathrm{Pb} \_\mathrm{W} \_\mathrm{B}$ 와 $\mathrm{ADHD}$ 간에 용량의존적 증가가 보이고 있음을 주목할 필요가 있다. 이는 혈중 납의 농 도가 증가하면 $\mathrm{ADHD}$ 가 심해진다는 주장에 대한 근거가 될 수 있는데, 한편, dad_edu_yr나 income의 경우 $\mathrm{ADHD}$ 와 음의 관계를 보이고 있는데, 이는 아버지의 교육 수준이 증가하고 소득수준이 증가할수 록 $\mathrm{ADHD}$ 증상을 덜 보이는 것으로 해석할 수 있으며, 비모수 함수로 추정된 소득수준 변수의 경우 일 정 수준까지 증가하는 동안은 $\mathrm{ADHD}$ 지표 추정치가 비교적 급격하게 떨어지다 일정 수준을 넘어서면 수평이 유지되는 것을 보이고 있다. 또한 fdr_neurop과 $\mathrm{ADHD}$ 도 양의 상관을 가지는데 부모가 신경정 신적 질환을 겪은 아동의 $\mathrm{ADHD}$ 점수가 높아짐을 알 수 있다.

\section{5. $\mathrm{BMDL}$ 의 산출 방법론 및 산출 결과}

\section{1. 준모수 회귀함수에서 $\mathrm{BMD}$ 를 찾는 특수성}

본 연구에서 $\mathrm{BMD}$ 는 사전에 정의되어 있는 일정한 수준(BMR) 만큼 $\mathrm{ADHD}$ 를 증가시킬 수 있는 혈중 납의 농도 $\left(\mathrm{Pb}_{-} \mathrm{W}_{-} \mathrm{B}\right)$ 를 의미한다. 앞서 식 $(2.2)$ 에서 살펴본 $\mathrm{BMD}$ 산출식은 선형 회귀모형을 이용하 는 경우에만 적용될 수 있으며, 본 연구에서와 같은 준모수 회귀함수를 이용하는 경우에 $\mathrm{BMD}$ 를 도출하 는 것은 좀 더 특수한 문제이다. 본 연구에서는 정해진 $\mathrm{BMR}$ 에 $\mathrm{Pb}-\mathrm{W} \_\mathrm{B}$ 가 0 일 때의 $\mathrm{ADHD}$ 추정치 평 균을 더한 뒤, 이 값을 만족하도록 하는 $\mathrm{Pb} \_\mathrm{W} \_\mathrm{B}$ 를 구함으로써 $\mathrm{BMD}$ 를 산출하였다. 구체적으로, 사전 에 정해져 있는 $\mathrm{BMR}$ 에 대하여 아래 식 (5.1)을 만족하는 Pb_W_B의 값이 BMD가 된다.

$$
\hat{f}(0)+\mathrm{BMR} \approx \hat{f}\left(\mathrm{~Pb}_{-} \mathrm{W} \_\mathrm{B}\right) .
$$

앞서 모형 2 로 추정된 준모수 회귀모형에 $\mathrm{Pb} \_\mathrm{W} \_\mathrm{B}$ 는 0 , 그 외 나머지 설명변수는 해당 변수의 평균값을 대입하여 $\hat{f}(0)$ 를 도출해 보았으며, 그 결과 $\hat{f}(0)=6.3249$ 로 추정되었다. 즉, 정해진 $\mathrm{BMR}$ 에 대하여 추정치가 $6.3249+\mathrm{BMR}$ 로 나오도록 하는 $\mathrm{Pb} \_\mathrm{W}_{-} \mathrm{B}$ 의 값을 찾아 이를 $\mathrm{BMD}$ 로 둘 수 있다. 

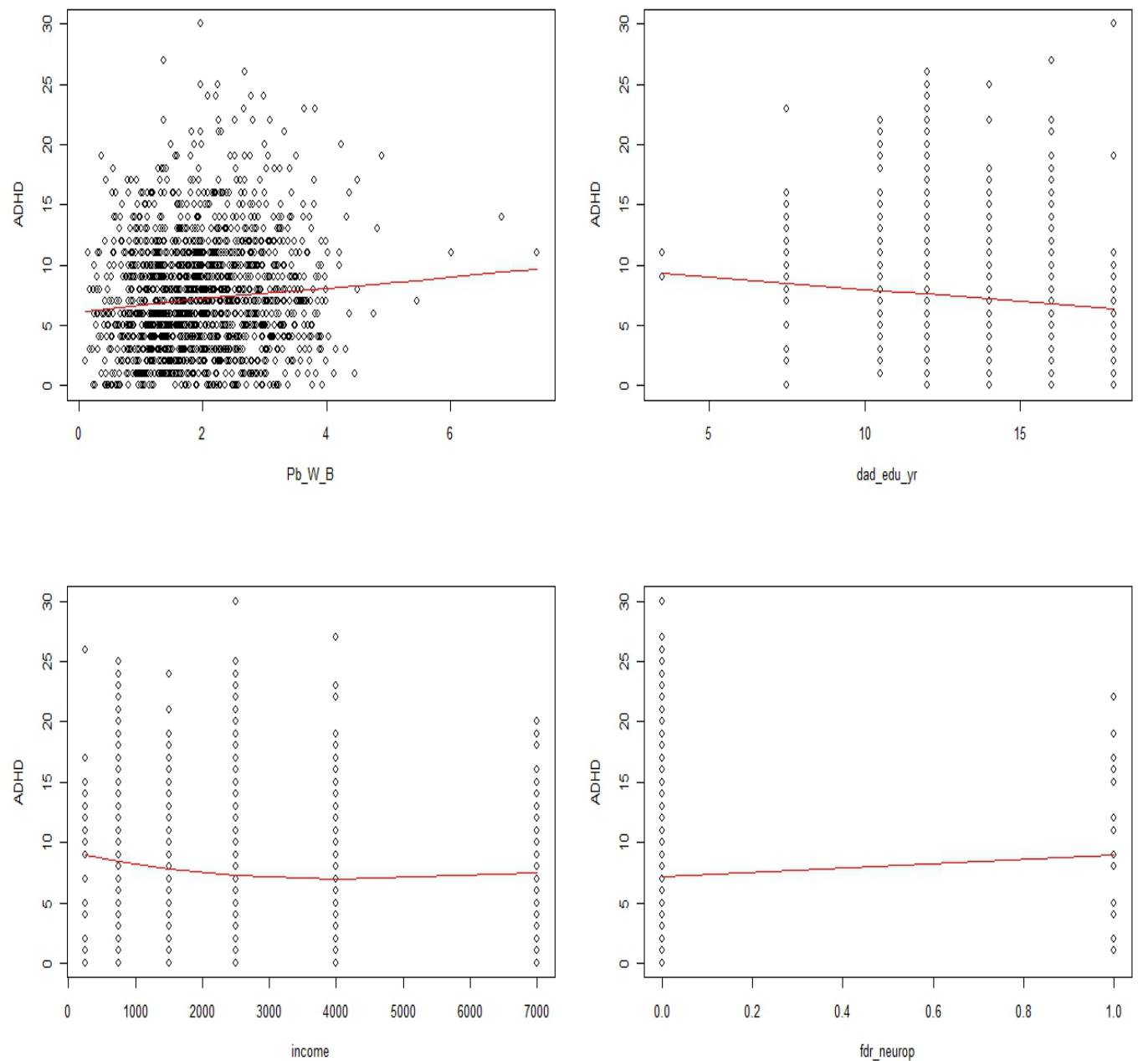

Figure 4.1. Scatter plots of ADHD versus major explanatory variable

\section{2. 도함수 산점도}

앞서 논의된 내용 중 $\left(\mathrm{Pb} \_\mathrm{W} \_\mathrm{B}, \hat{f}\left(\mathrm{~Pb} \_\mathrm{W} \_\mathrm{B}\right)\right)$ 가 단조 증가하는 형태인지 보다 엄밀히 파악하기 위하여 $\left.\hat{f}\left(\mathrm{~Pb}_{-} \mathrm{W}_{-} \mathrm{B}\right)\right)$ 에 대한 1 차 도함수와 그 $95 \%$ 신뢰구간을 도출해 보았다. 1차 도함수에 대한 신뢰구간의 하계가 0 보다 큰 경우에는 $\left.\hat{f}\left(\mathrm{~Pb}_{-} \mathrm{W}_{-} \mathrm{B}\right)\right)$ 이 단조 증가하는 형태가 통계적으로 유의하다고 해석할 수 있 다. 기존의 모형을 그대로 이용할 경우 $\hat{f}$ 에 대한 1 차 도함수는 0 이 되어 도함수 산점도를 도출할 수 없으므로, $\mathrm{Pb} \_\mathrm{W} \_\mathrm{B}$ 에 대한 2 차 항까지 포함한 준모수 회귀 모형으로 다시 적합해 줄 필요가 있다. 이 때 $\mathrm{Pb}_{-} \mathrm{W}_{-} \mathrm{B}$ 이외의 나머지 변수의 경우 $\mathrm{Pb}_{-} \mathrm{W}_{-} \mathrm{B}$ 에 대한 $\hat{f}$ 의 도함수 산점도에는 영향을 미치지 않으 므로 앞 모형과 동일하게 정의하였다. 이 경우 $\hat{f}$ 의 도함수와 도함수에 대한 $95 \%$ 신뢰구간은 앞서 모 형 1에서 비모수적 인자의 자유도를 결정하던 방법과 동일하게 원 모형을 혼합 효과 모형(Mixed Effect Model)로 재구성한 뒤 모수에 대한 BLUP 추정치를 이용하면 쉽게 도출할 수 있다 (Ruppert 등, 2003, 6.4절). 


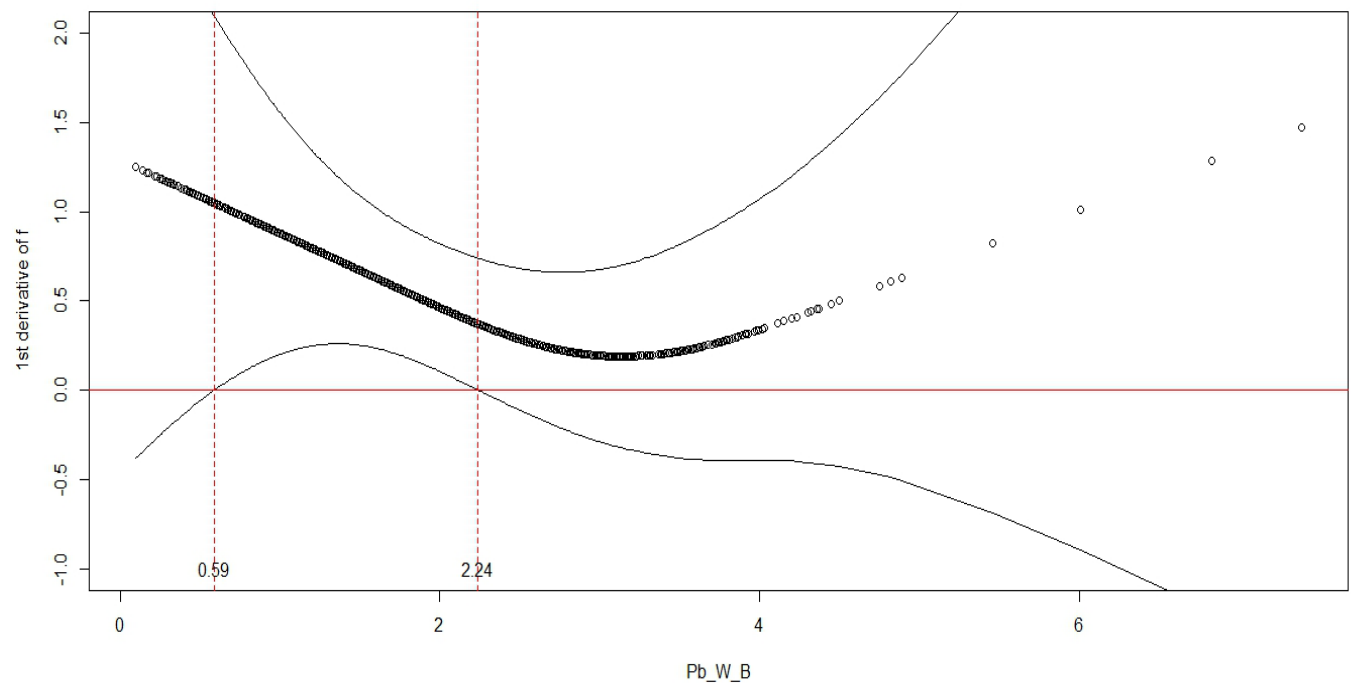

Figure 5.1. The first derivative and its variability band of ADHD against the blood lead concentration

이상의 과정을 통해 $\mathrm{Pb} \_$W_B에 대한 $\hat{f}$ 의 도함수 산점도를 도출한 결과는 아래 Figure 5.1과 같다. 도 함수 추정치는 모두 양의 값을 가지고 있으므로 $\mathrm{Pb}_{-} \mathrm{W}_{-} \mathrm{B}$ 에 대해 $f$ 는 단조 증가한다고 말할 수 있으나, 도함수 추정치의 신뢰구간을 살펴보면 $\mathrm{Pb} \_\mathrm{W}-\mathrm{B}$ 이 $1.5 \mu \mathrm{g} / \mathrm{dl}$ 를 기준으로 더 작아지거나 커질수록 변동 폭이 점차 커지는 것을 알 수 있다. 그래도 Pb_W_B가 $0.59-2.24 \mu \mathrm{g} / \mathrm{dl}$ 범위의 값에 대해서는 $f$ 가 단조 증가하는 형태를 가지는 것이 통계적으로 유의하다고 말할 수 있다. 앞서 밝힌 바와 같이 Lanphear 등 (2005)은 혈중 납 농도가 $7.5 \mu \mathrm{g} / \mathrm{dl}$ 보다 작은 경우에도 아동의 지적 발달을 저해할 수 있음을 밝혔는데, 이상의 결과에 의하면 이보다 횔씬 적은 수준인 $0.59-2.24 \mu \mathrm{g} / \mathrm{dl}$ 범위의 값에 대해서 아동의 행동장애에 미치는 효과가 통계적으로 유의하다는 점에서 의미가 있다.

\section{3. $\mathrm{BMD}$ 와 $\mathrm{BMDL}$ 의 산출}

아래 Figure 5.2 은 $\mathrm{BMR}$ 이 0.5 로 주어졌을 때 $\hat{f}(0)+\mathrm{BMR} \approx \hat{f}\left(\mathrm{~Pb}_{-} \mathrm{W} \_\mathrm{B}\right)$ 를 만족하는 $\mathrm{Pb} \_\mathrm{W} \_\mathrm{B}$ 를 도출 한 것이다. $\hat{f}$ 이 비선형 함수이므로 닫힌 해로 정리되지 않으므로, $\hat{f}(0)+\mathrm{BMR}$ 와 $\hat{f}\left(\mathrm{~Pb}_{-} \mathrm{W}_{-} \mathrm{B}\right)$ 의 차이 의 절대값이 가장 작을 때의 $\mathrm{Pb} \_\mathrm{W} \_\mathrm{B}$ 를 찾는 알고리즘을 이용하였는데 도출 결과 $\mathrm{BMD}$ 는 $0.84 \mu \mathrm{g} / \mathrm{dl}$ 였 다.

$\mathrm{BMDL}$ 은 앞서 구한 $\mathrm{BMD}$ 의 $95 \%$ 신뢰하계에 해당하는 값이다. 본 연구에서는 $\mathrm{Pb}-\mathrm{W} \_\mathrm{B}$ 와 $\mathrm{ADHD}$ 의 관계를 비모수로 가정하였기 때문에 $\mathrm{BMD}$ 의 $95 \%$ 신뢰하계를 구하기 위해서는 시뮬레이션을 통해 데이 터를 재생성한 뒤 $\mathrm{BMD}$ 를 도출하는 과정을 반복하여 $\mathrm{BMD}$ 의 분포를 통하여 구할 수 있다. 그 과정은 구체적으로 다음과 같다.

먼저 모형 2 를 혼합효과모형(Mixed Effect Model)로 변환하면 오차항과 랜덤효과 변수가 기대값이 0 인 정규분포를 따르게 되는데, 해당 변수 별 분산의 BLUP 추정치를 이용하여 오차항과 랜덤효과 변수 를 모든 자료 관찰치 수만큼 생성한다. 여기에 앞서 적합한 모형 2 의 계수 추정치를 반영하여 $\mathrm{ADHD}$ 변 수를 새로 생성해준다. 이렇게 새로 생성된 $\mathrm{ADHD}$ 변수와 기존의 모든 설명 변수를 모형 2 에 적용하여 다시 모형을 적합해 주면 새로운 $\mathrm{BMD}$ 를 도출할 수 있다. 이 과정을 10,000 번 반복하여 $\mathrm{BMD}$ 의 분포 


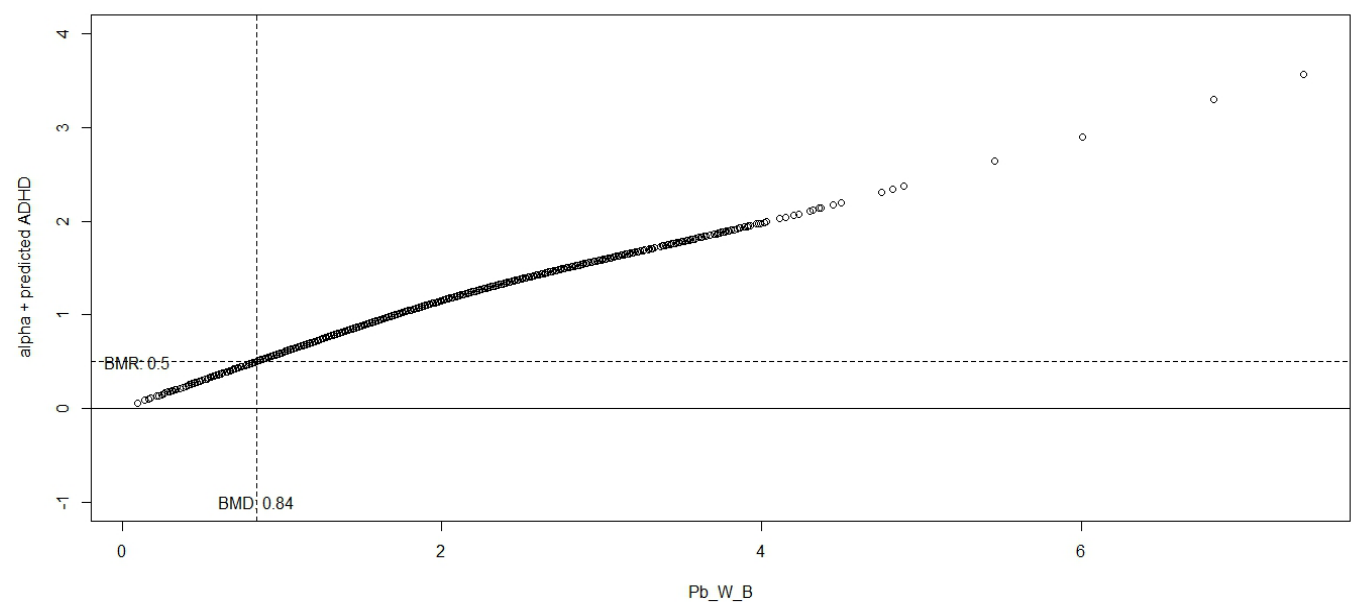

Figure 5.2. The BMD of the blood lead concentration which raises 0.5 (BMR) of ADHD
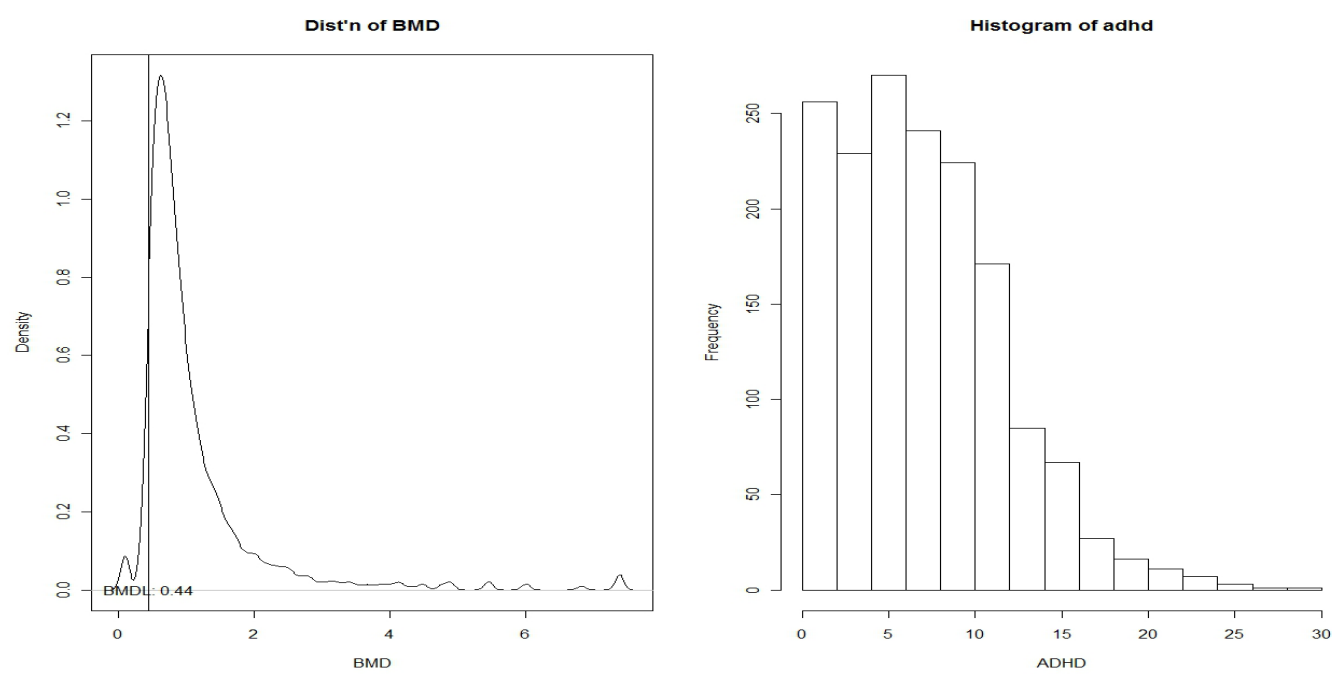

Figure 5.3. The distribution of BMD of the blood lead concentration which raises 0.5 of the ADHD, the $95 \%$ lower confidence limit(BMDL), and the histogram of ADHD

를 만들어낸 뒤, 그 분포에서 하위 $5 \%$ 의 퍼센타일에 해당하는 값을 찾아 그 값을 BMDL로 둔다. 이상의 방법으로 $\mathrm{BMD}$ 의 분포를 도출한 결과는 아래 Figure 5.3 (왼편)과 같으며, 분포의 $95 \%$ 신뢰하 계인 $\mathrm{BMDL}$ 은 $0.44 \mu \mathrm{g} / \mathrm{dl}$ 로 추정되었다.

\section{4. 변수 변환을 통한 모형 보정}

앞 절의 Figure 5.3(왼편)에서 $\mathrm{BMD}$ 의 분포는 양의 왜도를 갖는 형태를 보이고 있다. 이는 정규가정으 로부터의 이탈에서 기인하는 것인데, 아래 Figure 5.3(오른편)에서와 같이 $\mathrm{ADHD}$ 의 분포도 이와 유사 

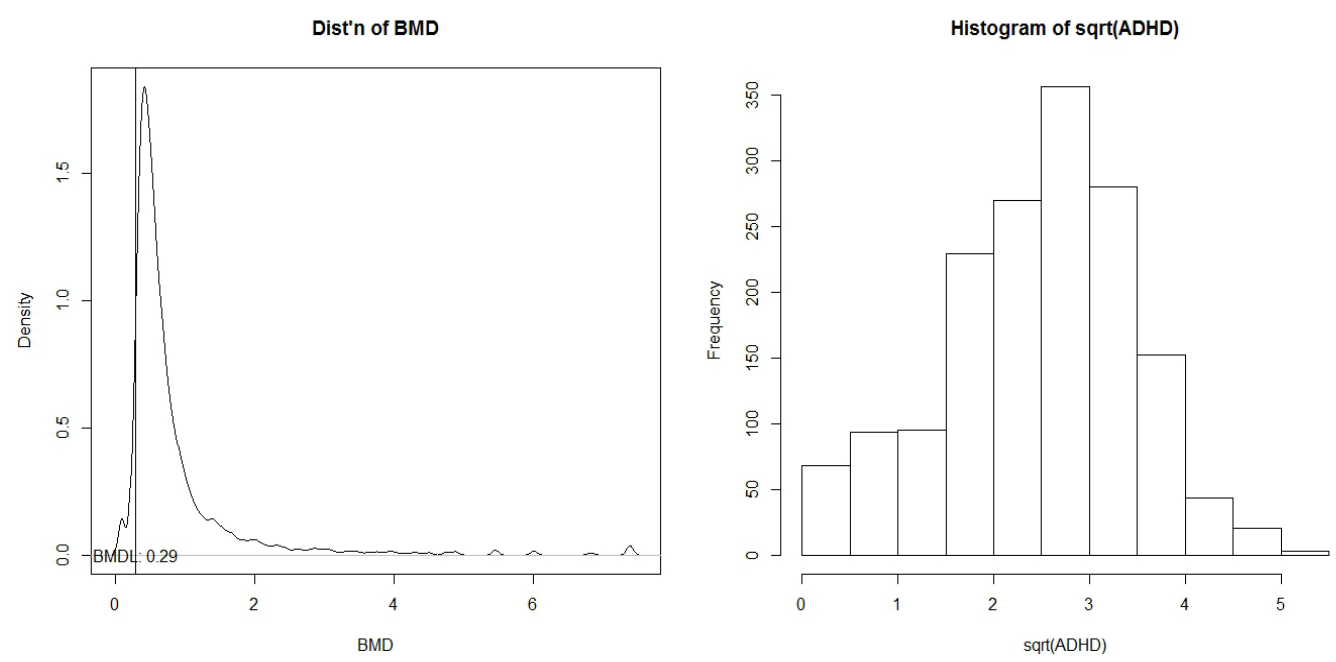

Figure 5.4. The distribution of BMD of the blood lead concentration which raises 0.1 of the square root of ADHD, the $95 \%$ lower confidence limit (BMDL), and the histogram of the square root of ADHD

Table 5.1. Comparison of BMDLs based on the original and the transformed models

\begin{tabular}{ccc}
\hline & 원 모형 결과 & 변수변환 모형 결과 \\
\hline 평균(표준편차) & $7.43(4.813)$ & $2.539(0.994)$ \\
$\mathrm{BMR}$ & 0.5 & 0.1 \\
$\mathrm{BMD}$ & 0.84 & 0.59 \\
$\mathrm{BMDL}$ & 0.44 & 0.29 \\
\hline
\end{tabular}

한 형태를 가지고 있어 $\mathrm{ADHD}$ 의 변수 변환을 고려해 볼 필요가 있어 보인다.

따라서 추가적으로 $\mathrm{ADHD}$ 변수에 제곱근을 취한 뒤, 앞서 논의된 것과 동일한 절차에 따라 모형을 추 정하고 $\mathrm{BMD}$ 와 $\mathrm{BMDL}$ 를 도출해 보았다. 제곱근을 취했을 때의 $\mathrm{BMD}$ 의 분포를 도출한 결과와 반응변 수의 히스토그램은 아래 Figure 5.4 와 같다. $\mathrm{BMD}$ 의 분포의 오른쪽 꼬리가 더 가늘어진 것을 확인하였 으며, 반응 변수도 보다 대칭형의 분포로 바뀌었음을 확인할 수 있다.

아래 Table 5.1은 원 모형에서의 결과와 변수변환된 모형에서의 결과를 종합적으로 비교한 것이다. $\mathrm{BMR}$ 의 경우 자료 분석 이전에 적정한 값을 미리 설정하기 어렵지만 반응변수의 $5 \%$ 또는 $10 \%$ 정도 의 적은 값을 두는 것이 일반적이며, 본 연구에서는 반응변수 표준편차의 약 $1 / 10$ 정도에 해당하는 값으 로 두었다. 즉, $\mathrm{ADHD}$ 를 이용한 모형의 경우는 $0.5, \mathrm{ADHD}$ 의 제곱근을 이용한 모형의 경우는 0.1 로 두 었다. 또한 각 $\mathrm{BMR}$ 에 대하여 $\mathrm{ADHD}$ 를 반응변수로 하는 모형의 $\mathrm{BMDL}$ 은 $0.44 \mu \mathrm{g} / \mathrm{dl}$ 이고, $\mathrm{ADHD}$ 의 제곱근을 반응변수로 하는 모형의 $\mathrm{BMDL}$ 은 $0.29 \mu \mathrm{g} / \mathrm{dl}$ 로 도출되었는데 $\mathrm{BMDL}$ 추정치가 모형 선택이 나 변수변환에 민감하게 변할 수 있다는 것을 감안했을 때 본 연구의 결과는 상당히 안정적인 것이라 말 할 수 있다. 비교를 위해 동일한 자료를 이용한 선형 회귀모형을 적합하여 $\mathrm{ADHD}$ 에 대한 $\mathrm{BMDL}$ 을 도 출한 $\mathrm{Kim}$ 등 (2011)의 결과를 아래 Table 5.2 에 정리하였다. 이 경우는 $\mathrm{ADHD}$ 의 제곱근을 반응변수 로 둔 모형과 $\mathrm{ADHD}$ 를 반응변수로 둔 모형간의 $\mathrm{BMLD}$ 의 차이는 최대 5 배 이상 정도 나는 것을 확인할 수 있다.

마지막으로 원 모형과 변수변환을 이용한 모형 각각에 대한 잔차 산점도와 잔차의 정규확률그림을 아래 
Table 5.2. BMDLs based on the linear regression models of Kim et al. (2001)

\begin{tabular}{cccc}
\hline & ADHD를 이용한 모형 & ADHD의 제곱근을 이용한 모형 \\
\hline Pb_W_B & 유의함 & 유의함 & 유의함 \\
sex & 유의함 & 유의함 & 유의함 \\
dad_edu_yr & 유의함 & 유의함 & 유의함 \\
smk_dur_preg & 유의함 & 유의함 & 유의함 \\
income & 유의함 & 유의함 & 유의함 \\
area(6 levels & 유의하지 않음 & 유의함 & 유의함 \\
alc_dur_preg & 유의함 & 유의하지 않음 & 유의하지 않음 \\
fdr_neurop & 유의함 & 유의하지 않음 \\
Pb_W_B & 유의하지 않음 & 제외 않음 & 유의함 \\
Pb_W_B & 유의하지 않음 & 제외 & 유의함 \\
BMR & 0.5 & 0.1 & 0.1 \\
BMD & 1.012 & 0.838 & 0.198 \\
BMDL & 0.749 & 0.612 & 0.130 \\
\hline
\end{tabular}
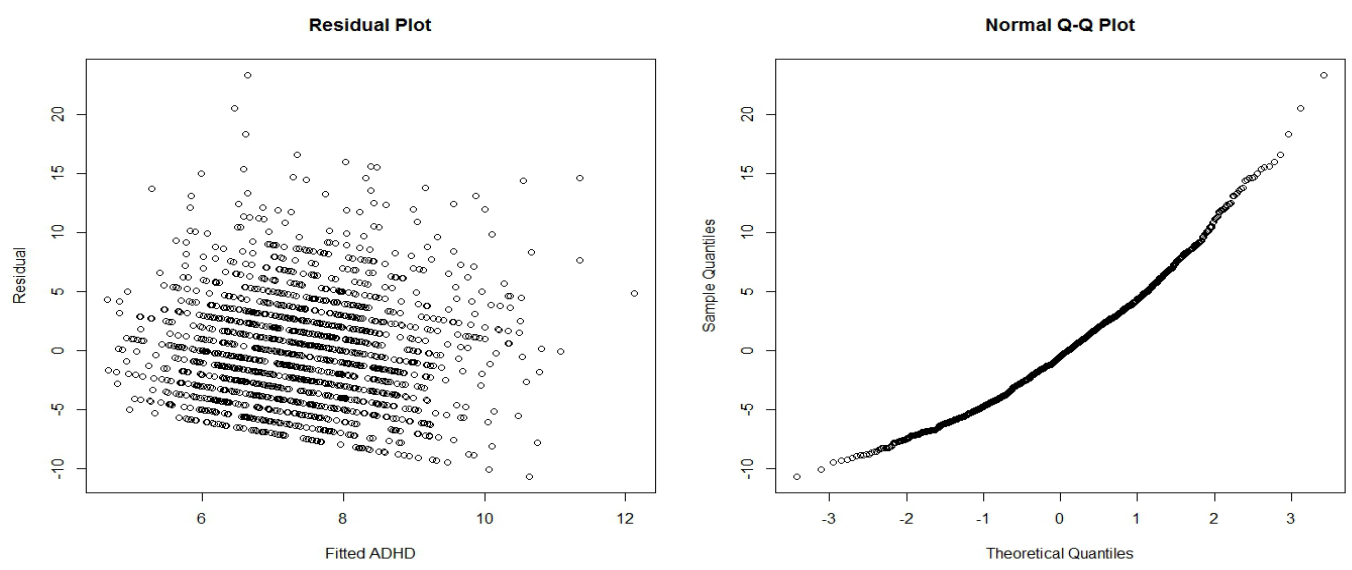

Figure 5.5. Residual plot of the original model and its normal probability plot

Figure 5.5와 Figure 5.6에 제시하였다. 두 모형의 모두 모형의 등분산성, 독립성 가정에 크게 문제가 없음을 확인할 수 있으며, 잔차의 분포도 정규분포로부터 크게 이탈하지 않았음을 확인할 수 있다.

\section{6. 토의 및 결론}

EFSA (2010a)에서 납의 위해평가를 하면서 세 가지 다른 종점에 대하여 각긱 다른 BMDL을 제시하였 다. $\mathrm{IQ}$ 를 종점으로 할 때 $1 \%$ 의 하락을 $\mathrm{BMR}$ 로 두고 구한 $\mathrm{BMDL}$ 은 $1.2 \mu \mathrm{g} / \mathrm{dl}$, 이완기 혈압 $1 \%$ 상승을 $\mathrm{BMR}$ 로 두고 구한 $\mathrm{BMDL}$ 은 $3.6 \mu \mathrm{g} / \mathrm{dl}$, 그리고 만성 신장병 발병율을 $10 \%$ 증가시키는 것을 $\mathrm{BMR}$ 로 할 때 구한 $\mathrm{BMDL}$ 은 $1.5 \mu \mathrm{g} / \mathrm{dl}$ 로 제시하였다. 본 연구에서는 $\mathrm{ADHD}$ 를 종점으로 사용하였고 $\mathrm{ADHD}$ 표준 편차의 $1 / 10$ 을 $\mathrm{BMR}$ 로 하여 $\mathrm{BMDL}$ 을 새롭게 제시하고 있다. 이를 위해 본 연구에서 사용한 $\mathrm{CHEER}$ 자료는 한국 아동의 건강, 특히 $\mathrm{ADHD}$ 지표로 표현될 수 있는 정신적 행동장애에 소량의 혈중 납 농도 가 어떠한 영향을 미칠 수 있는가에 대한 유용한 정보를 담고 있다. 이러한 CHEER 자료를 이용하여 

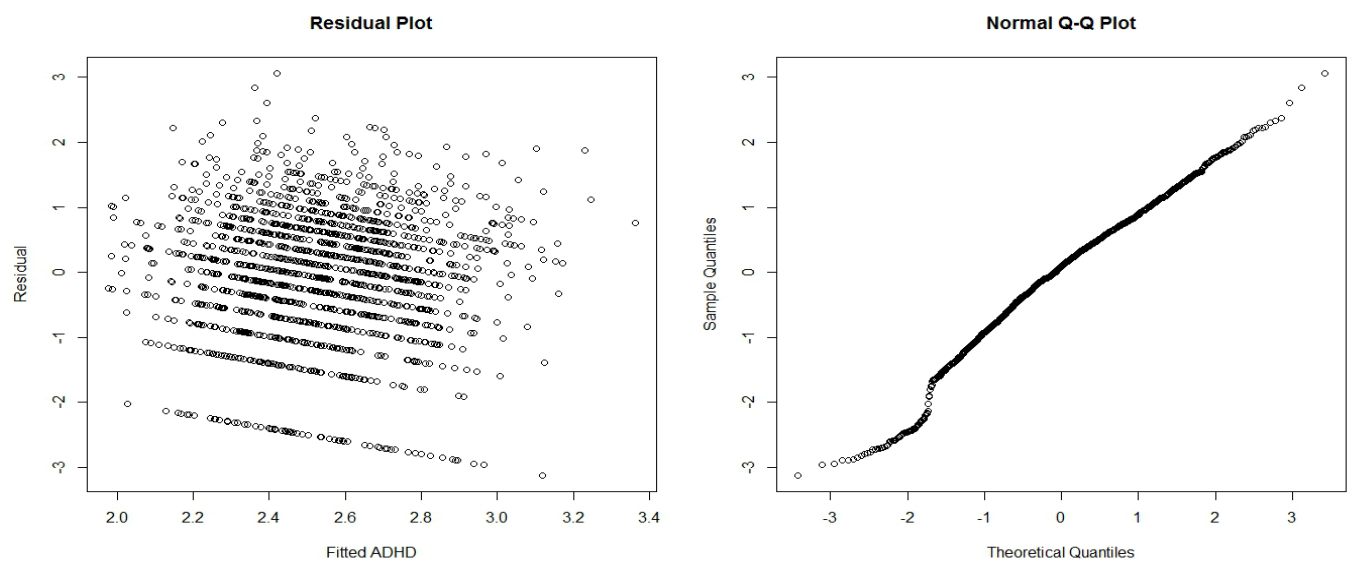

Figure 5.6. Residual plot of the transformed model and its normal probability plot

아동의 $\mathrm{ADHD}$ 지표를 소폭 상승시킬 수 있는 혈중 납 농도의 $\mathrm{BMDL}$ 을 산출하였으며, 그 결과 $\mathrm{ADHD}$ 지표 0.5 의 $\mathrm{BMR}$ 을 상승시키는 혈중 납 농도의 $\mathrm{BMDL}$ 은 $0.44 \mu \mathrm{g} / \mathrm{dl}$ 로, $\mathrm{ADHD}$ 의 제곱근 지표 0.1 의 $\mathrm{BMR}$ 을 상승시키는 혈중 납 농도의 $\mathrm{BMDL}$ 은 $0.29 \mu \mathrm{g} / \mathrm{dl}$ 로 각각 도출되었다.

Wheeler와 Bailer (2009)이 제안한 모형평균 방법을 참고하여, 각 모형에서 도출된 BMDL의 값을 해 당 모형 별 적합도를 나타내는 $\mathrm{AIC}$ 를 이용하여 가중평균하여 도출된 단일 $\mathrm{BMDL}$ 을 제안해 볼 수 있 다. 원 모형의 $\mathrm{AIC}$ 값이 변수변환을 취한 모형의 $\mathrm{AIC}$ 값에 비해 약 2.13 배 높으므로, 원 모형에서 나 온 BMDL의 가중치를 $1 /(1+2.13)$ 으로, 변환 모형에서 나온 BMDL의 가중치를 $2.13 /(1+2.13)$ 으로 두고 가중평균하면 $0.33 \mu \mathrm{g} / \mathrm{dl}$ 으로 도출된다. 따라서 $0.33 \mu \mathrm{g} / \mathrm{dl}$ 을 아동의 $\mathrm{ADHD}$ 증상에 관한 안전기 준을 산정하는 혈중 납 농도의 기준값으로 보는 것이 적절할 것으로 보인다. 이는 EFSA (2010b)에서 아동의 IQ 점수에 대해 산출한 $\mathrm{BMDL} 1.2 \mu \mathrm{g} / \mathrm{dl}$ 보다 낮은 수준이라는 점에서 주목할 필요가 있다. 또 한 본 연구에서는 준모수 회귀모형을 활용하여 이전 연구에서의 BMDL의 산출 값이 모형이나 변수 변 환 등에 민감한 부분을 어느 정도 극복하였다는 점이 진전이라 말할 수 있다.

\section{References}

National Health Insurance Corportation, Korea. (2012). Data request through personal communication.

Budtz-Jørgensen, E., Keiding, N. and Grandjean, P. (2001). Benchmark dose calculation from epidemiological data, Biometrics, 57, 698-706.

Canfield, R. L., Henderson, C. R. Jr., Cory-Slechta, D. A., Cox, C., Jusko, T. A. and Lanphear, B. P. (2003). Intellectual impairment in children with blood lead concentrations below 10 microgram per deciliter, The New England Journal of Medicine, 348, 1517-1526.

Crump, K. (1984). A new method for determining allowable daily intakes, Fundamental and Applied Toxicology, 4, 854-871.

Crump, K. (1995). Calculation of benchmark doses from continuous data, Risk Analysis, 15, 79-89.

EFSA (2010a). An international pooled analysis for obtaining a benchmark dose for environmental lead exposure in children. (Question $\mathrm{N}^{\circ}$. EFSA-Q-2009-01078).

EFSA (2010b). EFSA Panel on Contaminant in the Food Chain(CONTAM); Scientific Opinion on Lead in Food, EFSA Journal 2010, 8(4), 1570 [147pp]. doi:10.2903/j.efsa.2010.1570. Available online: www.efsa.europa.eu. 
Gaylor, D. W. and Slikker, W. Jr. (1990). Risk assessment for neurotoxic effect, Neurotoxicology, 11, $211-218$.

Ha, M., Kwon, H.-J., Lim, M.-H., Jee, Y.-K., Hong, Y.-C., Leem, J.-H., Sakong, J., Bae, J.-M., Hong, S.J., Roh, Y.-M. and Jo, S.-J. (2009). Low blood levels of lead and mercury and symptoms of attention deficit hyperactivity in children: A report of the children's health and environment research (CHEER), Neurotoxicology, 30, 31-36.

JECFA (2000) Evaluation of Certain Food Additives and Contaminants, WHO Technical Report Series, 896, 80-83.

Kim, B.-S., Ha, M. and Kwon, H.-J. (2011). A benchmark dose analysis for lead exposure on the attention deficit hyperactivity disorder data of Korean children, Biometrie und Medizinische Informatik, 18, 59-69.

Lanphear, B. P., Hornung, R., Khoury, J., Yolton, K., Baghurst, P., Bellinger, D. C., Canfield, R. L., Dietrich, K. N., Bornschein, R., Green, T., Rothenberg, S. J., Needleman, H. L., Schnaas, L., Wasserman, G., Graziano, J. and Roberts, R. (2005). Low-level environmental lead exposure and children's intellectual function: an international pooled analysis, Environmental Health Perspectives, 113, 854-899.

Ruppert, D., Wand, M. P. and Carroll, R. J. (2003). Semiparametric Regression, Cambridge University Press, New York.

So, Y. K., Kim, Y. S., Choi, N. K., Kim, S. J., Non, J. S. and Ko, Y. J. (2003). The reliability and validity of Korean Conner's parent and teacher rating scale, J Child Adolesc Psychiatry, 14, 183-194.

US CDC (1991). Preventing Lead Poisoning in Young Children: A Statement by the Centers for Disease Control. Atlanta, GA: Centers for Disease Control and Prevention.

US CDC (2005). MMWR. Morbidity and mortality weekly report, 54(20), 513-516.

Wheeler, M. W. and Bailer, J. A. (2009). Comparing model averaging with other model selection strategies for benchmark dose estimation, Environmental and Ecological Statistics, 16, 37-51.

WHO (1995). Environmental Health Criteria 165-Inorganic Lead. Geneva: International Programme on Chemical Safety, World Health Organization. 